\title{
Endoscopic removal of a fish bone piercing the bile duct after pancreaticoduodenectomy
}

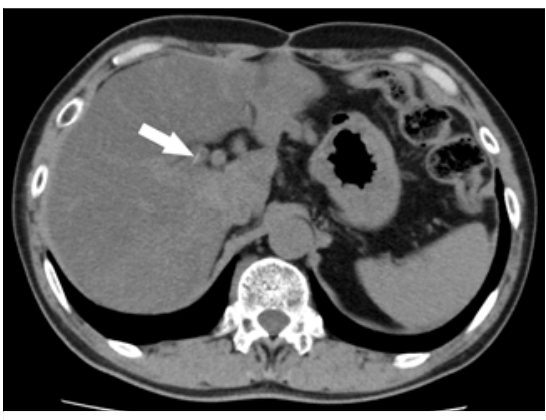

> Fig. 1 Computed tomography showing a linear radiopaque structure traversing from the bile duct to the right lobe of the liver, suggestive of a fish bone (arrow).

A 67-year-old man was referred to our endoscopy unit by a surgeon for endoscopic removal of a fish bone suspected on computed tomography (CT). The patient was diagnosed with pancreatic cancer 3 years previously and underwent pancreaticoduodenectomy with R0 resection. Follow-up CT revealed a linear radiopaque structure traversing from the bile duct to

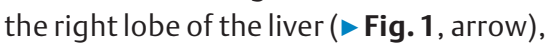
suggestive of a fish bone. He experienced vomiting once after eating a deep-fried sandfish 5 days earlier but had been asymptomatic since then. As he had no signs of cholangitis, he was followed on an outpatient basis for a while. However, CT performed 2 months later also indicated residual fish bone in the bile duct, and double-balloon endoscopy (DBE) was performed ( $\triangleright$ Video 1 ).

DBE revealed a relatively wide-open choledochojejunostomy anastomosis. By carefully observing inside the bile duct, a yellowish-brown structure piercing the bile duct wall was detected endoscopically ( $\triangleright$ Fig. 2 a, arrow). The object was grabbed with biopsy forceps. When pull tension was applied, bulging of the bile duct wall was observed on the distal side. The forceps were then pushed towards the proximal side, and a needleshaped elongated object popped out into the bile duct ( $\triangleright$ Fig.2 b). A balloon

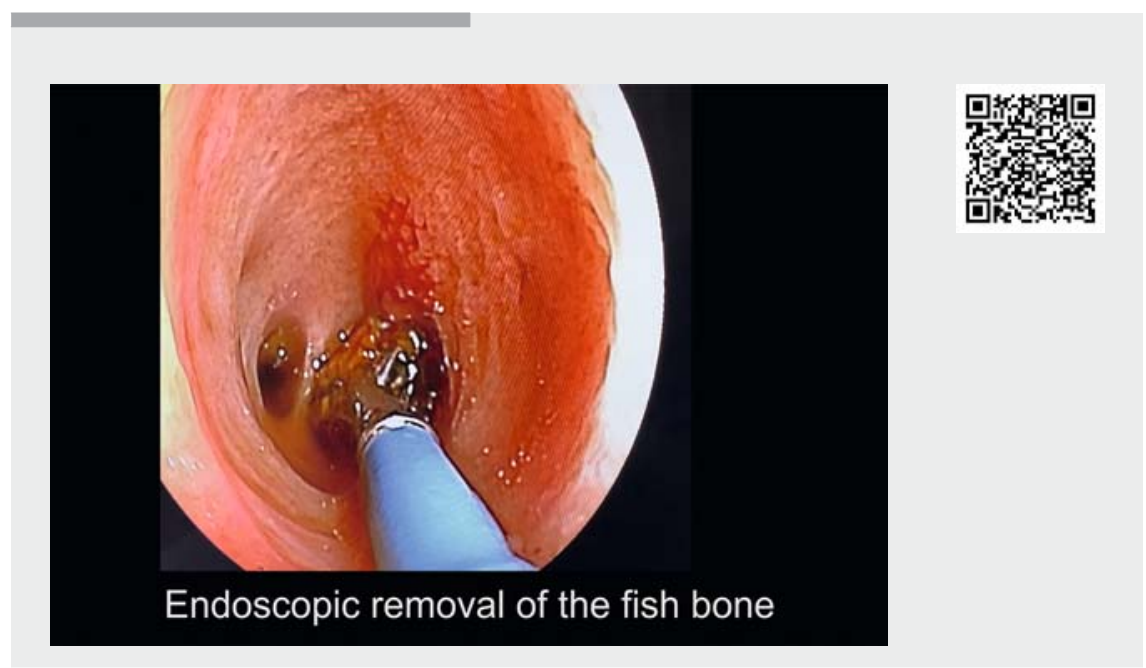

Video 1 Double-balloon endoscopy for removal of a fish bone piercing the bile duct after pancreaticoduodenectomy.
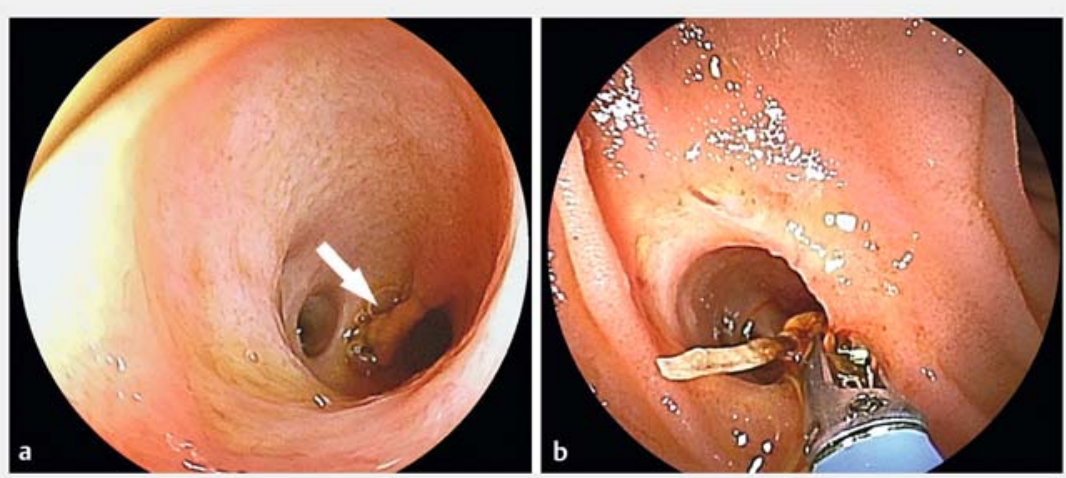

Fig. 2 Double-balloon endoscopy. a A yellowish-brown structure was seen piercing the bile duct wall (arrow). b A needle-shaped elongated object was pulled out from the bile duct.

cholangiogram showed no contrast leakage ( $\mathbf{F i g . 3}$ ). The object was withdrawn into the scope channel and removed along with the endoscope. The removed object measured $3 \mathrm{~cm}$ long and was most likely the bone of a sandfish ( $\triangleright$ Fig.4). Migration of fish bones to the bile duct is a possible complication following pancreaticoduodenectomy [1-3]. Intervention is controversial when the patient is asymptomatic, as some cases have been reported to disappear on subsequent CT [4]. However, considering the risk of stone formation and cholangitis, it seems reasonable to attempt endoscopic removal when migration remains on CT for a few months.

Endoscopy_UCTN_Code_TTT_1AQ_2AH 


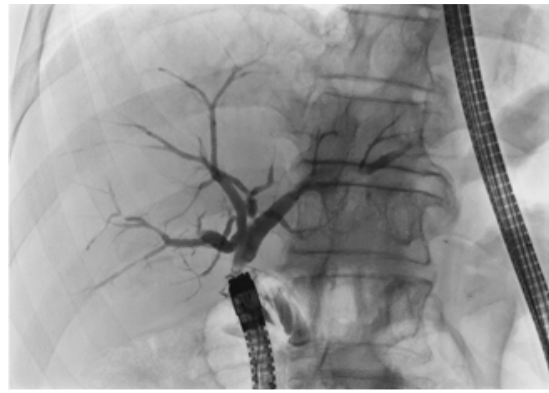

Fig. 3 Balloon cholangiogram performed after removal of the object showing no contrast leakage.

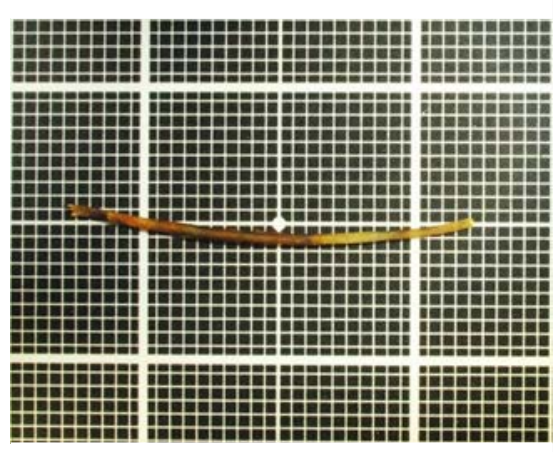

Fig. 4 A 3-cm-long object was removed from the bile duct and was most likely the bone of a sandfish.

\section{Competing interests}

The authors declare that they have no conflict of interest.

\section{The authors}

Takuya Ishikawa', Hiroki Kawashima², Eizaburo Ohno', Masanao Nakamura', Suguru Yamada $^{3}$, Masamichi Hayashi ${ }^{3}$, Mitsuhiro Fujishiro ${ }^{1}$

1 Department of Gastroenterology and Hepatology, Nagoya University Graduate School of Medicine, Nagoya, Japan

2 Department of Endoscopy, Nagoya University Hospital, Nagoya, Japan

3 Department of Gastroenterological Surgery (Surgery II), Nagoya University Graduate School of Medicine, Nagoya, Japan

\section{Corresponding author}

\section{Takuya Ishikawa, MD}

Department of Gastroenterology and Hepatology, Nagoya University Graduate School of Medicine, 65 Tsuruma-cho, Showa-ku, Nagoya 466-8550, Japan Fax: +81-52-7442785

ishitaku@med.nagoya-u.ac.jp

\section{References}

[1] Wu XL, Li SW. Biliary stricture caused by a fish bone masquerading as anastomotic recurrence from distal cholangiocarcinoma after pancreaticoduodenectomy. Am Surg 2020; 86: e1-e3

[2] Sakakida T, Sato H, Doi T et al. A bile duct stone formation around a fish bone as a nidus after pancreatoduodenectomy. Case Rep Gastroenterol 2018; 12: 69-75
[3] Koga Y, Soyama A, Kitasato A et al. Fishbone migration in the intrahepatic bile duct after pancreaticoduodenectomy. ACG Case Rep J 2018; 5: e18

[4] Akahane M, Kusakabe M, Murakami M et al. Fishbone migration to bile ducts after pancreaticoduodenectomy: a case series. Abdom Radiol (NY) 2019; 44: 1217-1222

Bibliography

Endoscopy 2021; 53: E164-E165

DOI 10.1055/a-1224-3724

ISSN $0013-726 X$

published online 20.8.2020

(c) 2020. Thieme. All rights reserved.

Georg Thieme Verlag KG, Rüdigerstraße 14, 70469 Stuttgart, Germany

\section{ENDOSCOPY E-VIDEOS}

https://eref.thieme.de/e-videos

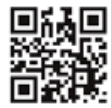

Endoscopy E-Videos is a free access online section, reporting on interesting cases and new techniques in gastroenterological endoscopy. All papers include a high quality video and all contributions are freely accessible online.

This section has its own submission website at https://mc.manuscriptcentral.com/e-videos 